\title{
CONTRIBUIÇÕES DO PENSAMENTO FEMINISTA PARA UMA EXPLICAÇÃO LOCALIZADA DA EDUCAÇÃO E DA APRENDIZAGEM
}

Etiane Araldi ${ }^{\mathrm{i}}$

\section{RESUMO}

$\mathrm{O}$ artigo parte de algumas questões que emergiram na experiência recente das ocupações dos estudantes secundaristas no Brasil, conforme depoimentos de estudantes de São Paulo e do Rio de Janeiro. Reconhecendo o protagonismo das mulheres nesse movimento, são articuladas contribuições de autoras feministas para o desafio de pensar práticas educacionais e explicações da aprendizagem que estejam atentas ao problema da convivência, tão bem enunciado pelos estudantes. Aborda perspectivas críticas a teorias clássicas da psicologia do desenvolvimento e da aprendizagem, com o objetivo de produzir outras explicações para o processo educacional, que considerem seu caráter localizado, no sentido proposto para esse termo por Donna Haraway. Para isso, propõe o deslocamento de concepções de sujeito e política pautadas por uma racionalidade masculina, autônoma, abstrata e impessoal.

Palavras chave: feminismo, educação, aprendizagem

\section{RESUMEN}

El artículo parte de algunas questiones que surgieron en la experiencia reciente de las ocupaciones de estudiantes secundaristas en Brasil, segundo testimonios de estudiantes de São Paulo e Rio de Janeiro. Reconociendo el protagonismo de las mujeres en ese movimiento, son articuladas contribuiciones de autoras feministas para el desafío de pensar prácticas educacionales y explicaciones del aprendizaje que estean atentas al problema de la convivencia, tan bien enunciado por los estudiantes. Aborda perspectivas críticas a las teorías clásicas de la psicología del desenvolvimento y del aprendizaje, con el objectivo de producir otras explicaciones para el proceso educacional, que consideren su carácter localizado, en el sentido propuesto para ese término por Donna Haraway. Para eso, propone el deslocamiento de concepciones de sujeto y política pautadas por una racionalidad masculina, autónoma, abstracta e impersonal.

Palabras clave: feminismo, educación, aprendizaje 
A estudante secundarista ${ }^{\text {ii }}$ nos conta como aprendeu, na ocupação de sua escola, que os problemas que surgem na convivência entre pessoas diferentes podem ser bem encaminhados se estas os acolhem e se propõem a, juntas, encontrarem soluções. Há, na sua fala, o encantamento de quem acabou de descobrir a potência do trabalho coletivo: "a gente consegue enxergar os problemas e propor (...) fico encantada com a criatividade, isso não era instigado na gente". Reconhece que é mais difícil "ficar horas discutindo para escolher o que é melhor pra gente", mas parece estar convicta de que esse é um exercício necessário para que se possa conviver.

Essa fala se deu no contexto das ocupações de estudantes secundaristas do Colégio Pedro II, rede de escolas federais no Rio de Janeiro, com as quais tivemos contato no final do ano de 2016, por meio de visitas e participação em eventos abertos ao público. Tais ocupações se articulavam a um movimento mais abrangente, abarcando escolas estaduais e municipais em diferentes pontos do estado e do país, na luta contra algumas medidas do governo federal que teriam impacto na educação: a Proposta de Emenda à Constituição (PEC) 55/2006 que previa o congelamento dos gastos públicos afetando as políticas sociais, a Reforma do Ensino Médio por meio da Medida Provisória (MP) 746/2016 e o programa Escola Sem Partido expresso no Projeto de Lei (PL) 193/2016

A ocupação estudantil como forma de resistência havia ganhado força no ano anterior, em São Paulo, como reação a uma proposta de reorganização escolar conduzida pelo governo do estado, que implicaria, entre outras questões, no fechamento de algumas escolas, obrigando muitos alunos a mudarem de instituição. Inspirados em um movimento ocorrido no Chile, diversas escolas foram, coletiva e espacialmente, ocupadas pelos secundaristas em diferentes pontos da capital e do interior.

Segundo Campos, Medeiros \& Ribeiro (2016), autores que analisaram esse movimento, "uma ocupação é uma forma muito singular de luta: pessoas se dispõem a viver juntas em um determinado espaço por tempo indeterminado, tendo que se organizar diariamente e lidar com suas necessidades de infraestrutura, alimentação, higiene, atividades etc.” (p.39). Dentro de uma proposta de autogestão, como foi a adotada por boa parte das escolas ocupadas, cada decisão exigia intensos processos de conversa e negociação coletiva, sendo as assembleias e comissões os principais dispositivos utilizados pelos(as) estudantes. De modo que a convivência e a horizontalidade são apontadas pelos autores como dois grandes desafios com os quais, corajosamente, os secundaristas se enfrentaram nesse processo.

Parece-nos particularmente interessante que essa aprendizagem de convivência ocorra justamente quando são incluídas no espaço escolar atividades tradicionalmente associadas ao domínio privado (cozinhar, limpar, cuidar das relações, dos espaços), o qual por sua vez esteve 
historicamente relegado às mulheres. O documentário sobre as ocupações em São Paulo "Lute como uma menina"iv aborda o protagonismo das mulheres nesse movimento e elucida a presença de mecanismos de ação e negociação coletiva como método para enfrentar as situações cotidianas das ocupações em que foram colocados em cena preconceitos de gênero e formas de divisão sexual do trabalho, como quando acontecia de os meninos não se envolverem nas atividades da cozinha.

De fato, diferentes autoras feministas têm apontado uma intrínseca relação entre o lugar das mulheres na cultura patriarcal e as políticas de conhecimento e educacionais dela decorrentes. Neste artigo, seguindo a pista do depoimento da estudante que abre este texto, articularemos alguns elementos do pensamento feminista que, a nosso ver, contribuem para o desafio de pensar práticas educacionais e explicações da aprendizagem mais atentas ao problema da convivência, tão bem enunciado pelos(as) secundaristas, e seu papel na constituição de sujeitos e na ação política.

Articulação é o termo utilizado por Latour (2008) na proposição de um conhecimento que não opere por correspondência a um referente, na lógica tradicional sujeito-objeto, e sim, que se construa por um acúmulo de experiências e na convergência entre vários elementos heterogêneos: humanos, não humanos, instrumentos. Aqui, ao recorrer a essa palavra, apontamos o sentido metodológico com que buscamos operar neste texto: nem buscando representar a experiência dos estudantes, tampouco o pensamento feminista em sua totalidade. Abordaremos elementos de um e outro naquilo que eles articulam com relação, sobretudo, ao problema do aprender a conviver, tema que tomamos como um fio condutor para as articulações que em seguida apresentamos e que tornou-se relevante para nós a partir do próprio contato com os(as) secundaristas e de nossa experiência profissional e de pesquisa no campo da psicologia.

\section{A produção de uma racionalidade masculina, autônoma e impessoal nas explicações sobre a aprendizagem}

No campo das explicações sobre a aprendizagem, a psicologia costuma ocupar um lugar de destaque, graças a uma série de estudos e teorias no âmbito da cognição e do desenvolvimento humano, construídas sobretudo no decorrer do século XX, que trouxeram grandes contribuições às práticas pedagógicas. São conteúdos obrigatórios em qualquer currículo de formação docente as teorias psicológicas da aprendizagem e do desenvolvimento cognitivo. Antunes (2008) aponta inclusive que a psicologia da aprendizagem foi sendo tomada, historicamente, como o principal fundamento da educação. 
Em pesquisa realizada acerca das práticas de formação de psicólogos e psicólogas, identificamos que estas tendiam a se desenvolver predominantemente em torno do estudo de textos de autores clássicos, os quais são em geral homens, brancos, americanos ou europeus (ARALDI, 2012). Em um campo disputado por uma diversidade de perspectivas epistemológicas e metodológicas, assume-se, ainda, que cada psicólogo ou psicóloga deve fazer uma escolha teórica. A teoria costuma ser entendida como condição a priori para situar qualquer intervenção ou explicação psi, havendo inclusive a prática de adoção do sobrenome do autor escolhido: freudiano, lacaniano, foucaultiano. Justifica-se essa necessidade sob o argumento de que cada uma das diferentes psicologias possuiria uma determinada visão de homem, cabendo aos psicólogos e psicólogas em formação escolherem aquela com a qual se identificam mais ${ }^{\nu}$. Tal processo ocorre como se fosse necessário primeiro construir em âmbito individual uma visão de homem, para só depois agir/intervir (ARALDI, MARASCHIN \& DIEHL, 2014).

Nossas experiências profissionais foram interpondo vários questionamentos a esses sentidos compartilhados nos espaços acadêmicos de formação psi. Primeiramente observamos ser extremamente difícil manter uma coerência entre nossa prática e alguma teoria no contato com situações, permeadas pela experiência avassaladora das desigualdades sociais em nosso país, que forçam nossa capacidade relacional e de invenção de dispositivos de intervenção. Hoje nos parece relevante perguntar: qual o sentido de se ter uma visão de homem a priori em um trabalho que se apresenta sempre como exigência de deslocar-se de si mesmo e entrar em contato com um outro (ou uma outra) diferente? Aquecidos pelos debates que ganham força no contemporâneo sobre as questões de gênero, caberia ainda abrir a questão: como ter uma visão de homem poderia nos ajudar a intervir com não homens?

Em seu trabalho sobre a ideia de liberdade em suas relações com a psicologia e a juventude, Mattos (2012) desenvolve como a teoria liberal produz uma teoria do sujeito, a qual incorpora uma série de características que seriam necessárias aos indivíduos considerados aptos à participação política e à vida em sociedade. A autora afirma que esse sujeito "caracteriza-se por sua coerência, sua racionalidade, sua capacidade de argumentação e de convivência com os demais dentro das regulamentações sociais" (p.80) e, ainda, que "o sujeito do liberalismo é, via de regra, o sujeito racional, autocentrado, capaz de reflexão e bom senso" (p.78).

Tais concepções ancoram em uma concepção de sujeito valores caros ao projeto moderno e criam condições para que uma ciência como a psicologia seja chamada a explicar e produzir conhecimento sobre como podem ser constituídas essas características no processo de desenvolvimento dos indivíduos ${ }^{\mathrm{vi}}$. Ora, tais valores são afirmados em um momento histórico em que apenas os homens, e determinados homens, tinham acesso à esfera pública. Desse modo, 
todos aqueles e aquelas que, por uma produção dessa mesma sociedade que se pretende liberal, estão em condição de servidão, dependência, ou que vivem uma vida não orientada pelas capacidades de abstração e argumentação lógica, deverão adequar-se a esse padrão de interação social e política (MATTOS, 2012). Do contrário, permanecerão sem voz nos jogos de saber e poder que sustentam a representação oficial da sociedade.

Obras como as de Jean Piaget, segundo a autora, destacam-se no projeto de explicar como as crianças se desenvolvem em uma trajetória que tem como fim a constituição do sujeito racional, expresso na capacidade de pensar formal e abstratamente como última etapa do desenvolvimento cognitivo $^{\text {vii }}$. Nas palavras de Mattos (2012):

\begin{abstract}
A criança, após seu desenvolvimento normal, passando por todas as etapas assinaladas e reconhecidas pela psicologia como "esperadas" e "desejáveis", irá finalmente se tornar um adulto capaz de abstração e de pensamento formal (e, com isso, capaz de ler, entender e respeitar as leis que regem sua sociedade), emancipado emocionalmente (não dependendo mais dos cuidados de seus familiares, e capaz de constituir sua própria família) e independente (aqui, a independência não deve ser entendida apenas em seu sentido de "autonomia", de pensamento próprio, mas também em seu sentido econômico: um sujeito preparado para o mercado de trabalho, que gera renda para si e para aqueles que dele dependem). (MATTOS, 2012, p.88)
\end{abstract}

Mas não apenas a psicologia do desenvolvimento se engaja nesse projeto de explicação e de produção do homem racional, autônomo e independente. Também a psicanálise reafirma esses ideais, conforme discutido por Benjamin (1987) em sua análise crítica acerca do Complexo de Édipo viii e sua utilização como norma. Segundo a autora, todo o processo de constituição do sujeito psíquico descrito por Sigmund Freud se pauta num ideário de progressiva autonomia da criança em relação a um período marcado pela dependência e pelos vínculos, os quais são identificados à figura da mãe. Trata-se, portanto, de um percurso que se encaminharia para a renúncia de uma experiência marcada pela lógica da conexão e do cuidado rumo à identificação com a figura paterna, orientada pela autoridade, impessoalidade e pelo controle do corpo feminino.

O problema desse modelo explicativo, que marca a visão psicanalítica do desenvolvimento humano, é que ele naturaliza a divisão sexual do trabalho em nossa sociedade, ao supor uma figura feminina realizando o cuidado e uma figura masculina exercendo a autoridade. Com isso, polariza em termos de gênero processos que poderiam estar conectados. Ao separar radicalmente processos de dependência e independência, vínculo e diferenciação, relegando o primeiro pólo a uma etapa primitiva da infância, institui uma forma de construção da autonomia que se dá pela via da dominação e da produção de uma racionalidade instrumental. Segundo Benjamin (1987), a valorização da autoridade paterna na narrativa edípica nos encaminharia para uma progressiva substituição de formas pessoais de sociabilidade por formas 
abstratas, burocráticas, na forma de uma generalização da racionalidade masculina, que apagam elementos importantes que estariam presentes se o modelo de racionalidade fosse feminino.

Tal perspectiva também é abordada por Gilligan (1982), que produziu uma crítica à teoria do desenvolvimento moral de Kohlberg, segundo a qual as mulheres não atingiriam o estágio mais avançado de julgamento com base em valores universais. Para a autora, se a racionalidade feminina fosse a norma poderíamos valorizar uma forma de pensamento que se mantém contextual e relacional, ao invés de considerar que uma socialização bem sucedida culminaria em uma crescente independência do ego com relação ao ambiente. No entendimento Benjamin (1986) é esse tipo de lógica que permite práticas sociais de objetificação e não responsabilização pelo outro.

Desse modo, segundo as referidas autoras feministas, algumas das explicações do desenvolvimento mais reconhecidas da psicologia acabam tendo como efeito instituir a ideia de um ser como pré-condição ao conhecer, que se constitui em referência a uma racionalidade muito específica, masculina, abstrata, independente do outro e das coisas, e marcada pela divisão sexual do trabalho. Obviamente esse ser não se constitui a partir de lugar nenhum, sendo importante acrescentar a essa discussão um elemento de localização territorial/cultural. Segundo Burman (2008), os manuais de Psicologia do Desenvolvimento tendem a construir como norma etapas e ciclos de vida que se referem a sociedades e classes sociais muito particulares, mas que são apresentados como conhecimento universal, com consequências colonizatórias, se analisado em termos dos impactos de sua apropriação em escala global.

No Brasil, temos um trabalho expressivo, conduzido na década de 90 pela psicóloga Maria Helena Souza Patto ${ }^{\text {ix }}$, que tornou evidente os riscos de se tomar o conhecimento psi de modo descolado dos processos de dominação social. Tomando como problema a questão do fracasso escolar das crianças brasileiras, Patto (2000) observou que o mesmo estava fortemente ancorado nas características de uma sociedade desigual, com os preconceitos de classe e raça dela decorrentes, somado às intervenções de uma psicologia que desconsiderava esses elementos. Sua pesquisa tomava como material de investigação os laudos de avaliação psicológica de crianças com dificuldades de aprendizagem, nos quais a autora se deparou com discursos que abstraiam os sujeitos de sua realidade social, escolar e familiar, reduzindo-os a chavões do conhecimento psi e, com isso, reforçando preconceitos e a própria reprodução da desigualdade em nossa sociedade.

A partir disso, a autora questiona: "que ciência é esta que invariavelmente culpa a vítima, imbuída da crença, tomada como verdade inquestionável, de que os reveses que castigam os vitimados são consequência natural de suas próprias características psíquicas?” (PATTO, 2009, 
p. 408). Essa pesquisadora brasileira nos confronta, portanto, com as nefastas consequências de se tomar o domínio do conhecimento e da aprendizagem como produtos de uma subjetividade individual, isolada dos processos que as constituem.

As teorias feministas ajudam a pensar como, nesse gesto, produz-se, ao mesmo tempo, a ideia de que o conhecimento parte da mente de um indivíduo e, ainda, referenciada a um homem que se situa no ponto mais alto de uma escala global de dominação. Segundo Harding (1993), é preciso considerar que praticamente todo o escopo teórico e conceitual das ciências humanas e sociais não foram fundamentados na experiência de mulheres, tampouco em problemas que lhes são relevantes. A autora afirma, ainda, que:

A própria teorização é, em si mesma, perigosamente patriarcal, porque presume a separação entre aquele que conhece e aquilo que é conhecido, entre sujeito e objeto, e supõe a possibilidade de uma visão eficaz, exata e transcendente, pela qual a natureza e a vida social tomam a perspectiva que nos parece correta. (HARDING, 1993, p.10)

Nesse mesmo sentido, Haraway (1995), em suas problematizações acerca da ciência para o feminismo, aponta que "apenas aqueles que ocupam as posições de dominadores são autoidênticos, não marcados, incorpóreos, não mediados, transcendentes, renascidos" (p.27). A autora discute a associação controversa da racionalidade a uma perspectiva masculina e do corpo às mulheres e a outros grupos situados na condição de específicos. Propõe uma redefinição do conceito de objetividade que considere a localização e a corporificação como ontológicos em qualquer ação de produção de conhecimento:

A objetividade revela-se como algo que diz respeito à corporificação específica e particular e não, definitivamente, como algo a respeito da falsa visão que promete transcendência de todos os limites e responsabilidades (...). A objetividade feminista trata da localização limitada e do conhecimento localizado, não da transcendência e da divisão entre sujeito e objeto. (HARAWAY, 1995, p.21)

Seria possível deslocar-se de um ideal de autonomia impessoal e abstrato rumo a uma explicação localizada da educação e da aprendizagem? Parece-me que a perspectiva feminista traz contribuições em ao menos três âmbitos que, para esse projeto, seriam fundamentais: a desconstrução de um ser (coerente, universal, dominante) como sede do conhecimento; a ênfase na ação corpórea e coletiva como inerente ao aprender; a denúncia dos mecanismos de opressão e dominação presentes em nossa relação com a ciência, teorias e conceitos - a qual, como veremos, tem sido reproduzida pelo modo como organizamos os próprios dispositivos educacionais e científicos. 


\section{Por uma organização dos dispositivos educacionais que possibilite uma política de convivência}

A fala da estudante secundarista que abriu esse texto se deu em um contexto em que as ocupações nas escolas do Rio de Janeiro começavam a vislumbrar o seu fim. Nesse cenário, era recorrente entre os(as) estudantes a preocupação sobre como seria possível manter esse modo de fazer das ocupações quando as aulas voltassem. Também recorrente era a afirmação de estudantes que diziam ter aprendido mais em uma semana de ocupação do que em anos de sala de aula ${ }^{\mathrm{x}}$. Diante desses enunciados, caberia perguntar: por que a sala de aula não comportaria a aprendizagem de convivência experienciada nas ocupações? Se atentarmos para as características desse dispositivo educacional, é fácil perceber como ele se coaduna perfeitamente com as explicações da aprendizagem enquanto processo de progressiva independência em relação ao ambiente, ao outro e às coisas: não importa o objeto estudado, as tecnologias utilizadas para a aprendizagem tendem a ser as mesmas: fala do professor, textos, escrita e leitura; o cenário é o mesmo: um cubículo quadrado com mesinhas e cadeiras de fórmica; professores e estudantes restringindo sua capacidade de interação e construção coletiva do conhecimento em discussões que se orientam referencialmente, e quase que exclusivamente, no conhecimento produzido em uma realidade social muito diferente.

Perguntamos: como é possível que ainda suportemos esse tipo de dispositivo de ensino, sobretudo diante de todas as demandas sociais do nosso país que não cessam de serem direcionadas à educação? É no mínimo curioso que a expectativa de que a educação produza outros mundos possíveis seja enunciada recorrentemente em diferentes contextos sem que se coloquem em questão os dispositivos e métodos utilizados no sistema educacional. Caberia questionar se haveria a preocupação mesma com a aprendizagem na organização mais corrente da sala de aula e se não seria a própria não variação dos métodos de acordo com o que se estuda que produz o sentido representacional e universalizante dos conhecimentos que são veiculados nos sistemas de ensino.

No cenário descrito pelas autoras feministas como hegemônico, podemos, de fato, entender as instituições educacionais como dispositivos de produção de uma racionalidade instrumental, liberal e heteronormativa. Mattos e Bertol (2015) analisam como a instituição escola atua na produção de corpos normatizados, por meio de práticas como o isolamento das crianças e jovens do convívio social mais amplo, do enquadramento e vigilância constantes e da produção do gênero através de divisões dos espaços que podem ser ocupados por meninos e meninas. Já Mattos et al. (2013) apontam que: 
No processo educacional, os que estão sendo ensinados percorrem um caminho em que suas experiências vão sendo cada vez mais desmaterializadas e desconsideradas na busca pelo resultado final da formação básica: a aquisição de certas "competências universais" (...) Dia após dia, os estudantes aprendem a pensar como se seus corpos não estivessem presentes na sala de aula, ou ainda, a despeito deles. (MATTOS ET AL., 2013, p. 371).

Desse modo, a escola moderna, segundo as autoras, promove uma verdadeira "descorporificação", através de diferentes dispositivos, que "em nome da racionalização, da normatividade e da abstração" negam tudo que é contextual no espaço escolar. (MATTOS ET AL., 2013, p. 371). Do ponto de vista da psicologia que é apropriada como mecanismo explicativo desses processos educacionais, vimos que ela atua no sentido de reforçar uma perspectiva marcadamente abstrata acerca da aprendizagem e do conhecimento. Mattos (2012) e Benjamin (1987) apontam como as teorias psicológicas, em especial a psicologia do desenvolvimento piagetiana e a psicanálise freudiana, esforçam-se por construir explicações da cognição humana que atendam ao ideal de uma racionalidade desincorporada. Já Burman (2008) identifica uma separação entre os domínios da cognição e da emoção nas explicações da psicologia do desenvolvimento.

Ora, tais discursos da psicologia reforçam aquilo que Burman (2008), Harding (1993) e Haraway (1995) desenvolveram acerca da desconsideração do corpo e do espaço na produção do conhecimento. Além disso, conforme discutido por Mattos (2012), as explicações psi sobre a aprendizagem acabam por justificar práticas que situam as crianças e o sistema educacional como alijados do fazer político. Ao explicar a educação em termos de capacidades individuais, o resultado é um modelo de escola preocupado mais com os conteúdos do que com as relações e dispositivos concretos que produzem subjetividades nesse espaço.

Essas considerações das pesquisadoras feministas permitem que compreendamos o descompasso, que vivenciamos hoje no contexto brasileiro, entre projetos como o "Escola Sem Partido"xi, que vem advogar por uma educação "apolítica" e as ocupações nas escolas em diferentes pontos do país que surpreendem a sociedade ao mostrarem que ali é, sim, lugar de fazer política. Ocupar a escola tem significado produzir concreta e espacialmente outros modos de aprender e outra relação com o conhecimento: o exercício de lidar coletivamente com a diferença em ações do cotidiano como cozinhar, limpar e cuidar das relações e dos espaços da escola; o conviver como forma eficaz de resolver os problemas: por meio da conversa e do encontro, as situações problema são analisadas e, coletivamente, encontradas as soluções. Esses gestos absolutamente inovadores engendrados pelas ocupações se chocam com o projeto de escola liberal analisado por Mattos (2012), dada a sua pretensão de formar um sujeito que 
idealmente seria autossuficiente, ao percorrer um caminho evolutivo no qual deveria distanciarse cada vez mais de sua dependência do outro e das coisas. Cabe registrar que as experiências dos estudantes secundaristas apontam para um caminho oposto, como pode ser observado no seguinte excerto do "Documento Final Extraído no Processo de Ocupação do Colégio Pedro II" no Rio de Janeiro:

Nós estudantes, diante de nossas experiências tanto no período letivo quanto no contexto das ocupações, entendemos que a integração da comunidade escolar (onde se inserem pais e responsáveis, professores, orientadores, funcionários administrativos, técnicos, terceirizados e estudantes) é a chave para uma escola viva que estabelece um profundo diálogo entre todos estes segmentos, acerca de todas as questões que envolvem o cotidiano escolar. O espaço físico da escola, seus métodos pedagógicos, suas dinâmicas de ensino e aprendizagem e o relacionamento diário entre as pessoas que participam do processo educacional é que vão identificar a escola democrática e participativa. ${ }^{\mathrm{xii}}$

Entrevemos, nessas demandas dos estudantes secundaristas, a afirmação da convivência como modo de fazer política. Campos, Medeiros \& Ribeiro (2016), em sua análise das ocupações em São Paulo, identificam nas relações afetivas com a escola o principal gatilho para a organização do movimento. Tal experiência provocada pelas ocupações dialoga, a nosso ver, com as proposições das pesquisadoras feministas que viemos elucidando neste artigo. O trabalho de Mattos (2012) evidencia a necessidade de se construírem outras formas de relação com a alteridade, não pautadas pelo poder de autoridade e pela reafirmação de um sujeito autocentrado. Já Benjamin (1987) propõe que o reconhecimento do outro pode ser visto como a culminação do processo de diferenciação do sujeito, tanto quanto a autonomia - ao contrário do que preconiza a solução evocada no Complexo de Édipo. Segundo a autora, desenvolver a consciência de si mesmo e a consciência do outro podem ser partes do mesmo processo, não havendo a necessidade de uma autoridade masculina que interrompa um processo de vínculo e cuidado, identificado às mulheres, para que se desenvolva um sujeito.

Do mesmo modo, em contraponto ao entendimento dominante do liberalismo, Mattos et al. (2013) reconhecem na experiência de cuidado uma potencialidade política, ao constituir uma relação de mútua dependência entre os sujeitos: "nessa perspectiva, a ação política surgiria da dependência, e não em detrimento dela, com o sentimento de responsabilidade e de dever agir frente ao outro" (p.370). A experiência das ocupações das(dos) secundaristas abre esse sentido de política no sistema educacional brasileiro, e por isso é de suma importância que as aprendizagens desse movimento sejam incorporadas na transformação dos dispositivos educacionais. Esse ato significativo de efetivamente ocupar o espaço da escola elucida como podem ser produzidas outras formas de conhecer quando se mudam as tecnologias e dispositivos 
utilizados e os relatos das experiências das ocupações oferecem-nos pistas sobre como eles podem ser reorganizados. Vejamos um depoimento de um estudante de São Paulo:

\begin{abstract}
Há exatos 7 dias, ocupávamos nossa escola. Foi um dia longo e cansativo, mas compensador. [...] Aqui, não só aprendemos a lutar por nossos direitos, mas a viver. [...] Não tem sido fácil muitas vezes concordar discordando. [...] Mas é para isso também que estamos aqui: aprender uns com os outros. Aceitar opiniões, diferenças... Ajudar o próximo e esquecer um pouco do nosso 'eu' [...]. As experiências que trocamos diariamente, seja numa roda de conversa, numa aula de física, num debate, numa assembleia, no nosso momento de almoço/ janta... São coisas que, no futuro, ninguém poderá roubar de nós. São coisas que estão vindo para nos ensinar e nos fazer crescer... Nos mostrando que podemos sim e que se formos JUNTOS, podemos mais ainda. É crescimento psicológico, também. [...] ${ }^{\text {xiii }}$ (CAMPOS, MEDEIROS \& RIBEIRO, 2016, p. 39)
\end{abstract}

A descoberta da ação coletiva enunciada pelos estudantes pode ser pensada a partir do que Haraway (1995) propõe acerca de uma certa desestabilização do eu como condição para se operar na lógica de uma objetividade corporificada, localizada: “o eu dividido e contraditório é o que pode interrogar os posicionamentos e ser responsabilizado" (p.12). Se na explicação piagetiana o sujeito cognoscente agiria sempre com vistas ao restabelecimento do equilíbrio segundo seus interesses individuais - em uma relação com a objetividade pautada pela incorporação dos objetos ao eu (MATTOS, 2012) - na perspectiva feminista, pensaríamos esse sujeito do conhecimento de modo menos onipotente e coerente:

O eu cognoscente é parcial em todas suas formas, nunca acabado, completo, dado ou original; é sempre construído e alinhavado de maneira imperfeita e, portanto, capaz de juntar-se a outro, de ver junto sem pretender ser outro. Eis aqui a promessa de objetividade: um conhecedor científico não procura a posição de identidade com o objeto, mas de objetividade, isto é, de conexão parcial. (HARAWAY, 1995, p.26)

A autora afirma, ainda, que a "divisão, e não o ser, é a imagem privilegiada das epistemologias feministas do conhecimento científico" (HARAWAY, 1995, p.26). De modo que uma explicação localizada da aprendizagem teria como efeito reconhecer as mediações como constitutivas da ação de conhecer, apontando outro papel para a psicologia em relação a esse problema. Não mais uma psicologia que fundamenta o conhecer no homem, mas que reconhece as relações e os dispositivos como ontológicos ao aprender. Essa psicologia poderia desviar-se dos problemas identificados, ainda na década de 90, pelos estudos do fracasso escolar (PATTO, 2000, 2009) e aproximar-se dos clamores que têm sido trazidos, mais contemporaneamente, pelos estudantes secundaristas brasileiros. Como bem colocado por outro estudante de São Paulo, em um depoimento que tratava das vantagens dos métodos participativos de gestão das ocupações: "a necessidade de ter um líder às vezes afeta a capacidade cognitiva das pessoas" xiv (CAMPOS, MEDEIROS \& RIBEIRO, 2016, p. 39). Diante disso, urge que afirmemos uma outra 
concepção de sujeito, capaz de nos fazer avançar na construção de uma sociedade efetivamente democrática, como muito bem nos apresentam Mattos et al. (2013):

\begin{abstract}
Se partimos de uma concepção de sujeito que, para participar do mundo público e da vida em coletividade, não precisa superar as relações de dependência com outros sujeitos tornando-se independente, ou, em outras palavras, se entendemos que a noção de sujeito independente liberal é uma ficção que se promove às custas do silenciamento e do apagamento de intensas redes de cuidados, trocas, colaboração e interdependência nos mais diversos níveis, surge a possibilidade das relações na escola serem pensadas em outro registro que não o de mera tutela. Nesse registro marcado pelo cuidado, surgem cumplicidades e trocas que aproximam as diferentes posições. (MATTOS ET AL., 2013, p.374)
\end{abstract}

Nesse sentido, é possível encontrar no trabalho das autoras feministas perspectivas que contribuem para deslocar concepções de sujeito e política que não incluem as mulheres e, com isso, excluem parte do que os(as) secundaristas apontaram sob o sentido de convivência: a construção de relações, cuidado, interdependência. Pensamos que a colocação em cena desses elementos nas ocupações demanda nossa atenção e nosso esforço na produção de explicações mais localizadas, vinculadas e situadas, da educação e da aprendizagem.

Sim, que aprendamos com as mulheres que é pela conexão, e não pela separação, que se produzem sujeitos e mundos. Que aprendamos com as pesquisadoras feministas que todos, independentemente de gênero, estamos conectados, corporificados, em relações de mútua dependência. Por fim, que aprendamos com as(os) estudantes secundaristas que foi com essas ferramentas que se pôde fazer um dos movimentos políticos mais importantes da história recente da educação em nosso país.

\title{
Referências:
}

ANTUNES, M. A. M. Psicologia escolar e educacional: História, compromissos e perspectivas. Revista Semestral da Associação Brasileira de Psicologia Escolar e Educacional, v. 12, n. 2, p. 469-475, 2008.

ARALDI, E. Das escolas e escolhas teóricas às políticas cognitivas: legitimando a experiência e a contingência na colocação do problema do conhecer e do conhecimento psi. Dissertação de Mestrado. Instituto de Psicologia, Universidade Federal do Rio Grande do Sul, UFRGS, Porto Alegre, 2012.

ARALDI, E.; MARASCHIN, C. \& DIEHL, R. Por um modo mais incorporado de explicar o fazer do psicólogo. Psicologia: Ciência e Profissão, v. 34, n. 2, p. 420-443, 2014.

BENJAMIN, J. The decline of the Oedipus Complex. In: BROUGHTON, J.M. (Ed.), Critical Theories of Psychological Development, p. 211-244. Nova York: Plenum Press, 1987. 
BURMAN, E. Discourses of the child. In: Deconstructing Developmental Psychology, p. 67-84. Londres: Routledge, 2008.

CAMPOS, A.J.M.; MEDEIROS, J. \& RIBEIRO, M.M. Escolas de luta. São Paulo: Veneta, 2016.

FREUD, S. A dissolução do complexo de Édipo. Edição Standard Brasileira das Obras Psicológicas Completas, Vol. XIX, p. 215-226). Rio de Janeiro: Imago, 1974.

GILLIGAN, C. In a diferent voice: psychological theory and woman's development. Cambridge: Harvard University Press, 1982.

HARAWAY, D. Saberes localizados: a questão da ciência para o feminismo e o privilégio da perspectiva parcial. Cadernos Pagu, v. 5, p.07-41, 1995.

HARDING, S. A instabilidade das categorias analíticas na teoria feminista. Revista de Estudos Feministas, v. 1, n. 1, p. 7-31, 1993.

LATOUR, B. Como falar do corpo? A dimensão normativa dos estudos sobre a ciência. Em: J.

A. Nunes, R. Roque (orgs.). Objectos impuros: experiências em estudos sobre a ciência, p. 3961. Porto: Edições Afrontamento, 2008.

MATTOS, A. Da criança da psicologia do desenvolvimento ao cidadão da política liberal. Em: MATTOS, A., Liberdade, um problema do nosso tempo: os sentidos de liberdade para os jovens no contemporâneo, p. 77-127. Rio de Janeiro: Editora FGV, 2012.

MATTOS ET AL. O cuidado na relação professor-aluno e sua potencialidade política. Estudos de Psicologia, v. 18, n.2, p.369-377, abr./jun., 2013.

MATTOS, A. \& BERTOL, C. Oficinas de sexualidade nas escolas: saberes, corpo e diversidade. In: MARTINS ET AL., Intersecções em Psicologia Social: raçaletnia, gênero, sexualidades, p. 130-150. Florianópolis: ABRAPSO, 2015.

PATTO, M. H. S. A produção do fracasso escolar: histórias de submissão e rebeldia. São Paulo: Casa do Psicólogo, 2000.

PATTO, M.H.S. De gestores e cães de guarda: sobre psicologia e violência. Temas em Psicologia, v. 17, n. 2, p. 405-415, 2009.

PIAGET, J. Seis estudos de psicologia. Rio de Janeiro: Forense-Universitária, 1986.

\footnotetext{
i Psicóloga (UFRGS), Mestre em Psicologia Social e Institucional (UFRGS), Doutoranda em Psicologia Social (UERJ). Analista de Políticas Sociais no Ministério da Saúde.

ii Depoimento de uma estudante ocupante do Colégio Pedro II Campus Humaitá proferido em um evento sobre as ocupações no Rio de Janeiro do qual participei. Tratava-se de uma Jornada organizada pelo Sindicato dos
} 
Professores do Colégio Pedro II realizada no dia 06/12/2016 com o tema "As Ocupações do CP II: Autonomia, Horizontalidade e Autogestão na Educação". Essa fala ocorreu na Mesa "Ocupações: A reinvenção da escola Como a instituição das ocupações, seu cotidiano e sua forma de lidar com as dificuldades abrem novos horizontes para instituição escolar?". Para mais informações sobre o evento, consultar: https://www.facebook.com/events/146417352504134/, acessado em 15/01/2017.

iii Tais matérias estão disponíveis nos seguintes links: https://www25.senado.leg.br/web/atividade/materias//materia/127337, $\quad$ https://www25.senado.leg.br/web/atividade/materias/-/materia/126992, http://www25.senado.leg.br/web/atividade/materias/-/materia/125666, acessados em 02/05/2017.

${ }^{\text {iv }}$ Disponível no YouTube através do link: https://www.youtube.com/watch?v=8OCUMGHm2oA, acessado em $10 / 01 / 2017$.

${ }^{\vee}$ Em pesquisa realizada com estudantes de graduação em psicologia da Universidade Federal do Rio Grande do Sul (UFRGS), a identificação foi apontada como principal critério para a escolha teórica de psicólogos e psicólogas em formação (ARALDI, 2012).

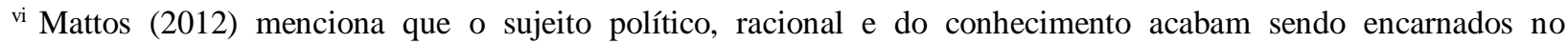
indivíduo.

vii Escapa ao escopo deste artigo o aprofundamento acerca da teoria de Jean Piaget, mas indicamos que as principais ideias do autor que foram objeto das críticas feministas que aqui desenvolvemos podem ser encontradas em Piaget (1986).

viii O Complexo de Édipo, cuja perspectiva freudiana encontra-se bastante disseminada em nossa cultura, foram desenvolvidas em diferentes pontos da obra de Freud. Para a discussão que aqui propomos, a principal referência é Freud (1974/1924).

ix A principal referência para essa perspectiva de estudos do fracasso escolar é o livro, publicado originalmente em 1990, intitulado: “A produção do fracasso escolar: histórias de submissão e rebeldia” (PATTO, 2000).

x São inúmeras as reportagens e discursos sobre as ocupações estudantis que trazem esse enunciado. Para citar algum sugerimos o já célebre discurso da estudante Ana Júlia realizado em outubro de 2016 na Assembleia Legislativa do Paraná, o qual pode ser acessado na íntegra pelo link: https://www.youtube.com/watch?v=2XGEyaiHWpk, acessado em 20/12/2016.

xiPara uma discussão mais detalhada acerca desse programa e seus impactos na educação brasileira, recomendamos a livro organizado por Frigotto (2017).

xii Documento assinado pelos estudantes das ocupações de diversos Campus do Colégio Pedro II, instituição de educação básica federal localizada no estado do Rio de Janeiro, o qual pode ser consultado pelo link: http://www.cp2.g12.br/images/comunicacao/2017/JAN/reivindicacao_alunos.pdf, acessado em 19/04/2017.

xiii Depoimento de aluno da Escola Estadual Romeu de Moraes, São Paulo, colhido no Facebook e citado em Campos, Medeiros \& Ribeiro, 2016, p. 39.

${ }^{x i v}$ Depoimento de aluno da Escola Estadual Ana Rosa, São Paulo, colhido no Facebook e citado em Campos, Medeiros \& Ribeiro, 2016, p. 39. 